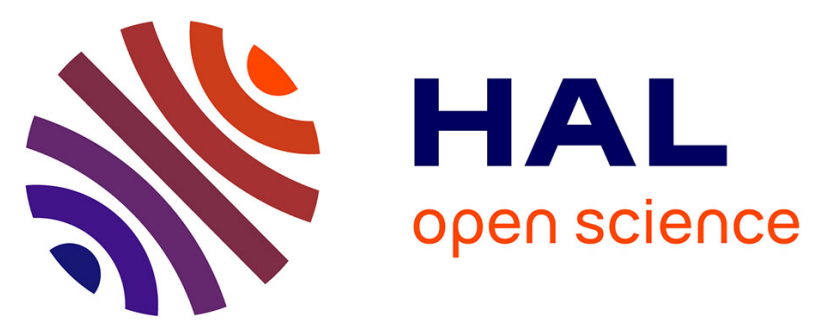

\title{
Improvement of the power response in contrast imaging with transmit frequency optimization
}

Sébastien Ménigot, Anthony Novell, Ayache Bouakaz, Jean-Marc Girault

\section{To cite this version:}

Sébastien Ménigot, Anthony Novell, Ayache Bouakaz, Jean-Marc Girault. Improvement of the power response in contrast imaging with transmit frequency optimization. IEEE International Ultrasonics Symposium (IUS), Sep 2009, Rome, Italy. pp.1-4, 10.1109/ULTSYM.2009.5441554 . hal-00599154v2

\section{HAL Id: hal-00599154 \\ https://hal.science/hal-00599154v2}

Submitted on 4 Jun 2012

HAL is a multi-disciplinary open access archive for the deposit and dissemination of scientific research documents, whether they are published or not. The documents may come from teaching and research institutions in France or abroad, or from public or private research centers.
L'archive ouverte pluridisciplinaire HAL, est destinée au dépôt et à la diffusion de documents scientifiques de niveau recherche, publiés ou non, émanant des établissements d'enseignement et de recherche français ou étrangers, des laboratoires publics ou privés. 


\title{
Improvement of the power response in contrast imaging with transmit frequency optimization
}

\author{
Sébastien Ménigot ${ }^{1}$, Anthony Novell ${ }^{1}$, Ayache Bouakaz ${ }^{1}$, Senior Member, IEEE and Jean-Marc \\ Girault $^{1}$, Member, IEEE \\ ${ }^{1}$ Université François Rabelais de Tours, Tours, France \\ INSERM, U930, Tours, France \\ CNRS, ERL 3106, Tours, France
}

\begin{abstract}
Conventionnal ultrasound contrast imaging systems use a fixed transmit frequency. However it is known that the insonified medium (microbubbles) is time-varying and therefore an adapted time-varying excitation is expected. We suggest an adaptive imaging technique which selects the optimal transmit frequency that maximizes the contrast tissue ratio (CTR). Two algorithms have been proposed to find an US excitation for which the frequency has been optimal with microbubbles.

Simulations were carried out for encapsulated microbubbles of $2 \mu \mathrm{m}$-radius by considering the modified RayleighPlesset equation for a $2.25 \mathrm{MHz}$ transmitted frequency and for various pressure levels ( $20 \mathrm{kPa}$ up to $420 \mathrm{kPa})$. In vitro experiments have been carried out using a $2.25 \mathrm{MHz}$ transducer and using a programmable waveform generator. Responses of a $1 / 2000$ blood mimicking fluid-diluted solution of Sonovue ${ }^{\mathrm{TM}}$ were measured by a $3.5 \mathrm{MHz}$ transducer.

We show through simulations that our adaptive imaging technique allows to reduce the transmit maximal pressure. As for in vitro experiments the CTR can reach $10 \mathrm{~dB}$.

By proposing a close loop system whose frequency adapts itself with the perfused media, throughout the examination, the optimization system adapt itself to the remaining bubbles population thus allowing an increase of the $30 \%$ examination duration.
\end{abstract}

Keywords - Adaptive imaging, contrast agent, optimization

\section{INTRODUCTION}

$\mathrm{U}$ LTRASOUND (US) contrast imaging is being investigated for tissue function and for targeted therapeutic applications with microbubble ultrasound contrast agents (UCA). Currently technical challenge consists in seeking for an US excitations which should make possible the optimization of the contrast tissue ratio (CTR). This ratio (eqn. 1) can be maximized if the microbubbles backscattered power is maximized. The transmit signal is a factor tours.frsebastien.menigot@etu.univ-tours.fr, jean-marc.girault@univ-tours.fr

(C) 2009 IEEE. Reprinted, with permission, from Sébastien Ménigot, Anthony Novell, Ayache Bouakaz and Jean-Marc Girault, Improvement of the power response in contrast imaging with transmit frequency optimization, 2009 IEEE International Ultrasonics Symposium (IUS), 20-23 Sept. 2009. This material is posted here with permission of the IEEE. Such permission of the IEEE does not in any way imply IEEE endorsement of any of the Université François Rabelais de Tours' products or services. Internal or personal use of this material is permitted. However, permission to reprint/republish this material for advertising or promotional purposes or for creating new collective works for resale or redistribution must be obtained from the IEEE by writing to pubs-permissions@ieee.org. of the microbubbles backscattered power.

$$
C T R=\frac{E_{\text {bubbles }}}{E_{B M F}}
$$

with $E_{\text {bubbles }}$ the microbubbles backscattered power and $E_{B M F}$ the tissue backscattered power.

We tackled the problem in a simple way by proposing an adaptive imaging technique which seeks the transmit frequency that maximizes the backscattered power. The use of an adaptive technique is justified by the fact that:

1. during the clinical examination, the insonified medium perfused by the microbubbles is a non-stationary medium (the concentration and the size of bubbles change...);

2. the pressure level is unknown because of the diffraction and attenuation effects which vary from one patient to another ;

3 . the size and the distribution of the UCA are not precisely known and can differ from one sample to another.

To overcome these problems, that is to disregard these unknown factors, it seemed more judicious to propose an US excitation whose frequency is selected in an adaptive way.

\section{Methods AND Materials}

\section{A. Methods}

The optimization aims to maximize the power of the backscattered signal by an iterative method. The principle consists in measuring the backscattered power from the microbubbles, for a sinus wave excitation first ; secondly in seeking for the optimal transmit frequency by maximizing the backscattered power.

The sinus pulse has been modulated with a Gaussian window(fig. 11) [1] to avoid the destruction of the microbubbles. The number of cycles has been fixed to 4 , whereas the amplitude has been corrected so that the power level was the same for every frequency. Two algorithms have been chosen to find the frequency of the transmit signal which maximizes the backscattered power : the golden section search and the gradient ascent. This choice was obvious because the analytic expression of power according to frequency is unknown.

- Golden section search(GSS) 2. This approach has been chosen because it does not need to compute the 


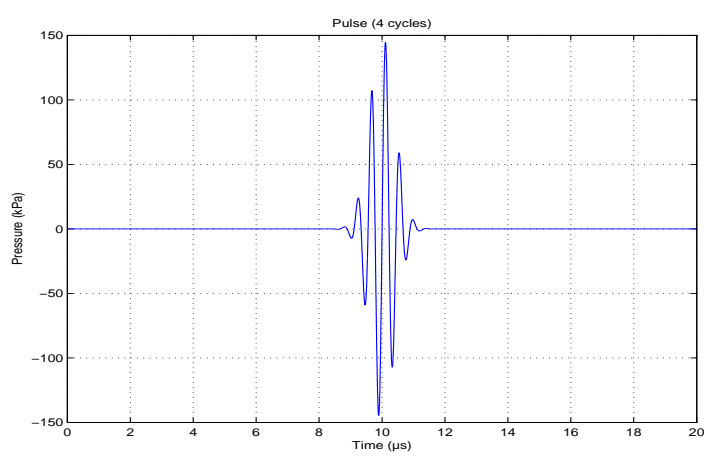

Fig. 1

EMISSION SIGNAL WITH 4 CYCLES

derivative of power. The first step consists in choosing two frequencies $\left(f_{1}\right.$ and $\left.f_{2}\right)$ in the analyzed bandwidth and to compute respectively their powers $\left(E_{1}\right.$ and $\left.E_{2}\right)$. A third frequency $f_{3}$ is deduced such as the intervals where the power is maximal, is reduced. In the next iteration, from a reduced intervals, a new frequency $f_{3}$ is computed to approach the optimal frequency.

- Gradient ascent(GA) 3]. This one maximizes power with a recurrence relation.

$$
f_{k+1}=f_{k}+\alpha_{k} \cdot \nabla E\left(f_{k}\right)
$$

The gradient is estimated with the discrete gradient. This ratio is nearly null for small power in comparison with the frequency and thus the parameters were normalized.

$$
\nabla E\left(f_{k}\right)=\frac{E_{k}-E_{k-1}}{f_{k}-f_{k-1}}
$$

For every sign change of two successive gradients, $\alpha_{k}$ is divided by two.

\section{B. Materials}

\section{B.1 Microbubbles}

The ultrasound contrast medium was composed of Sonovue $^{\mathrm{TM}}$ microbubbles. The mean diameter is $4.5 \mu \mathrm{m}[4]$ and the shell thickness $d_{S e}$ is $1 \mathrm{~nm}[5]$. As for the mechanical shell properties, the shear modulus $G_{s}$ is $46 \mathrm{MPa} 6$ ] and the shear viscosity is $1 \mathrm{~Pa} \cdot \mathrm{s}$.

\section{B.2 Numerical simulations}

Numerical simulations for encapsulated contrast bubbles were resolved, using Bubblesim[7], from the modified Rayleigh-Plesset equation. The Sonovue ${ }^{\mathrm{TM}}$ properties were used for the microbubbles parameters.

The microbubble echo was computed from only one microbubble immersed in blood. The blood density is 1025 $\mathrm{kg} \cdot \mathrm{m}^{-3}$ and the velocity of sound in blood is $1570 \mathrm{~m} \cdot \mathrm{s}^{-1}$.

The transducers effects have been considered. Each transmit and received signals were filtered by the bandwidth of the transmit and the received transducers respectively.

\section{B.3 Acoustical Measurements}

Each method was compiled using Matlab® (Mathworks, Natick, MA). The resulting excitation signal was transmitted through a GPIB port (National Instruments, Austin, TX) to an arbitrary function generator (33220A, Agilent, Palo Alto, CA). The signal was then amplified using a power amplifier (Amplifier Research 150A100B, Souderton, PA) and transmitted to a $2.25 \mathrm{MHz}$ PZT single element (Sofranel, Sartrouville, France) focused at $55 \mathrm{~mm}$ and with a bandwidth of $74 \%$ (fig. 2).

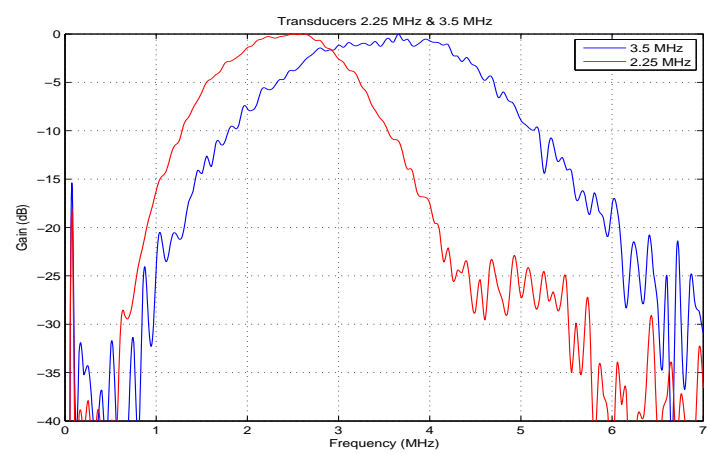

Fig. 2

BANDWIDTH OF TRANSDUCERS

Responses of a $1 / 2000$ diluted solution of Sonovue ${ }^{\mathrm{TM}} \mathrm{mi}-$ crobubbles (Bracco Research, Geneva, Switzerland) were measured by a $3.5 \mathrm{MHz}$ PZT single element transducer with a bandwidth of $63 \%$ (fig. 2) also focused at $55 \mathrm{~mm}$ and used in receive mode.

The first transducer was used to transmit the signal, whereas the second wich was placed perpendicularly was used to receive the microbubbles echo. This position avoided direct transmission .

Measured echoes were amplified by $30 \mathrm{~dB}$ (PulserReceivers 5072R, Olympus Panametrics, Waltham, MA, USA) and then visualized on a digital oscilloscope (Tektronix, Beaverton, OR). Signals were transferred to a personal computer through a GPIB port for further analysis. Finally, each signals were compensated by received transducer bandwidth.

The backscattered power was computed from a linear combination of twenty signals, to cancel out the motion of microbubbles. For each iterations, twenty pulses were transmitted and twenty signals were received. With a principal component analysis (PCA), a new received signal which allows to deduce the backscattered power, is computed.

To deduce the contrast tissue ratio (CTR), the microbubbles were injected in a blood mimicking fluid(BMF) "'EUDFS-BMF-ver.1.2"' (Dansk Fantom Service, Jyllinge, Denmark). For each frequency, the BMF received power (without microbubbles) was determined. 


\section{RESUlts}

\section{A. Simulations}

To know the evolution power according to the frequency, a microbubble has been stimulated with 4 cycles and the backscattered signal has been computed for different pressures.

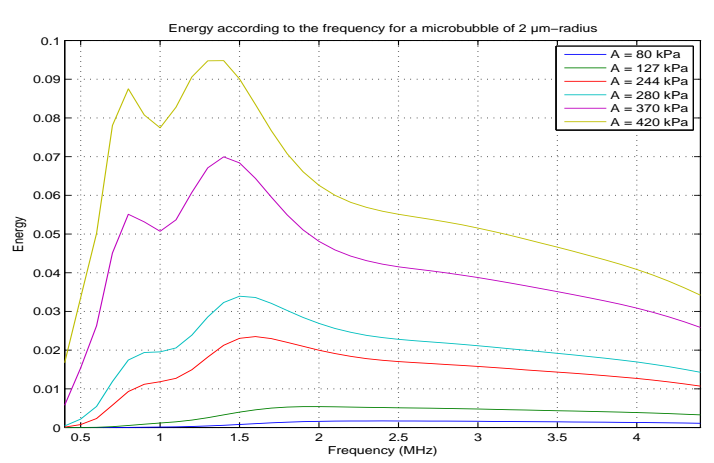

Fig. 3

Power ACCORDING TO THE FREQUENCY FOR A 2-MICRONS MICROBUBBLE

The frequency which allows to obtain a maximum power varies with the pressure: for a high pressure, the frequency is lower (fig 3). From the appearance of power, the initial frequencies for the algorithms have been chosen to find the global maximum.

The two methods were applied with three signals of 127 , 244 and $370 \mathrm{kPa}$ maximal pressure.
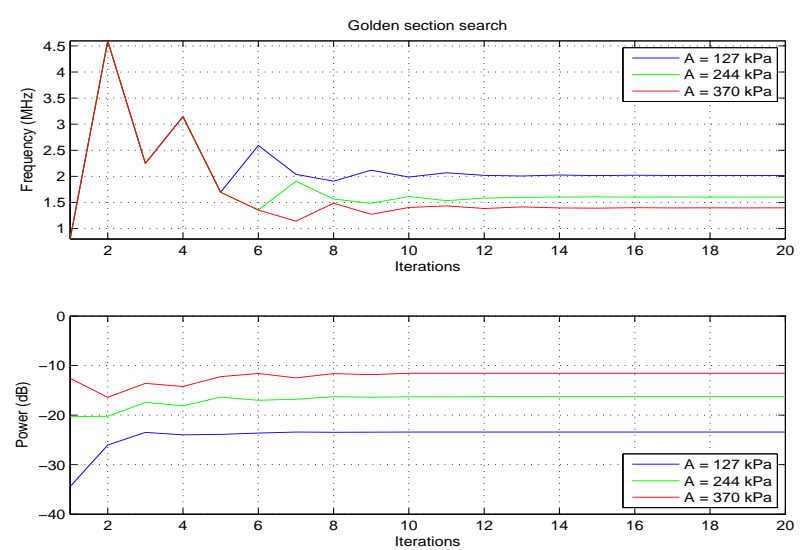

Fig. 4

Golden section search FOR a 2-Microns microbubble

The backscattered power was stable and maximize after twenty iterations. For each pressure, the optimal frequency is different $(2 \mathrm{MHz}, 1.6 \mathrm{MHz}$ and $1.39 \mathrm{MHz}$ respectively for 127,244 and $370 \mathrm{kPa}$ ), which was shown by the power according to the frequency.

For a backscattered power, the maximal pressure could be reduced with an optimal frequency III-A When the signal was transmitted with a $244 \mathrm{kPa}$ pressure (respectively
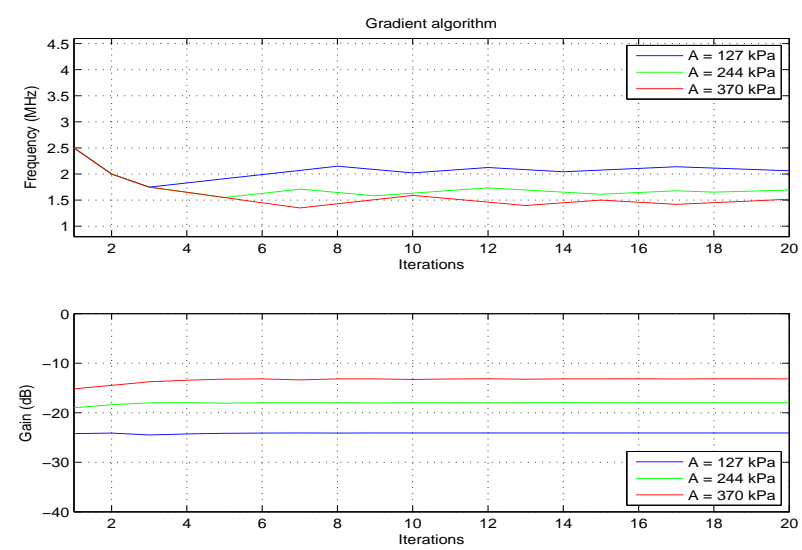

Fig. 5

Gradient ascent for a 2-microns microbubble

\begin{tabular}{lllll}
\hline $\begin{array}{l}\text { Backscattered } \\
\text { Power }\end{array}$ & WO & GSS & GA \\
\hline$-17.4 \mathrm{~dB}$ & pressure $(\mathrm{kPa})$ & 244 & 222 & 222 \\
& frequency $(\mathrm{MHz})$ & 2.25 & 1.65 & 1.64 \\
\hline$-13.6 \mathrm{~dB}$ & pressure $(\mathrm{kPa})$ & 370 & 308 & 308 \\
& frequency $(\mathrm{MHz})$ & 2.25 & 1.48 & 1.46 \\
\hline
\end{tabular}

TABLE I

Pressure for the optimal (Golden section search - GSS and Gradient Ascent - GA) and the transducer central FREQUENCIES (Without OPTIMiZATion - WO) With THE SAME BACKSCATTERED POWER IN SIMULATION

$370 \mathrm{kPa}$ ) and with the $2.25 \mathrm{MHz}$ transducer central frequency, the maximal pressure could be reduced to $22 \mathrm{kPa}$ (respectively $65 \mathrm{kPa}$ ) with the same backscattered power.

\section{B. Experiments}

A cloud of microbubbles immersed in BMF has been stimulated with two different pressures (244 and $370 \mathrm{kPa})$.
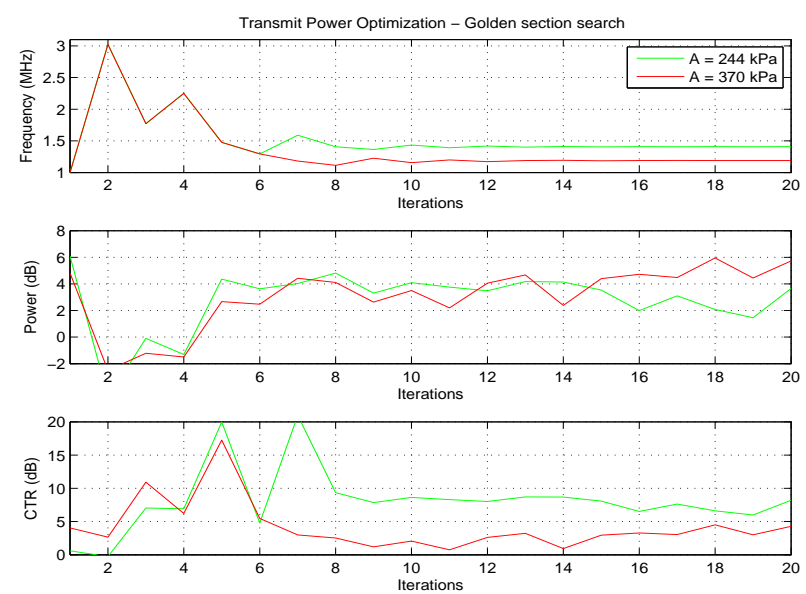

Fig. 6

EXPERIMENT WITH GOLDEN SECTION SEARCH 


\begin{tabular}{lllll}
\hline $\begin{array}{l}\text { Backscattered } \\
\text { Power }\end{array}$ & WO & GSS & GA \\
\hline $5 \mathrm{~dB}$ & pressure $(\mathrm{kPa})$ & 244 & 222 & 222 \\
& frequency $(\mathrm{MHz})$ & 2.25 & 1.45 & 1.18 \\
& LP (dB/min) & 0.096 & 0.079 & 0.014 \\
& DEG (\%) & & 21.12 & 37.06 \\
\hline $6.6 \mathrm{~dB}$ & pressure $(\mathrm{kPa})$ & 370 & 305 & 305 \\
& frequency (MHz) & 2.25 & 1.61 & 1.27 \\
& LP (dB/min) & 0.15 & 0.053 & 0.13 \\
& DEG $(\%)$ & & 12.54 & 16.95 \\
\hline
\end{tabular}

TABLE II

Pressure for the optimal (Golden section search - GSS and Gradient Ascent - GA) and the transducer central FREQUENCIES (Without optimization - WO) With the SAME BACKSCATTERED POWER in vitro, LOSS POWER (LP) AND DURATION EXAMINATION GAIN (DEG) WITH OPTIMIZATION COMPARED WITH THE CASE Without OPTIMIZATION
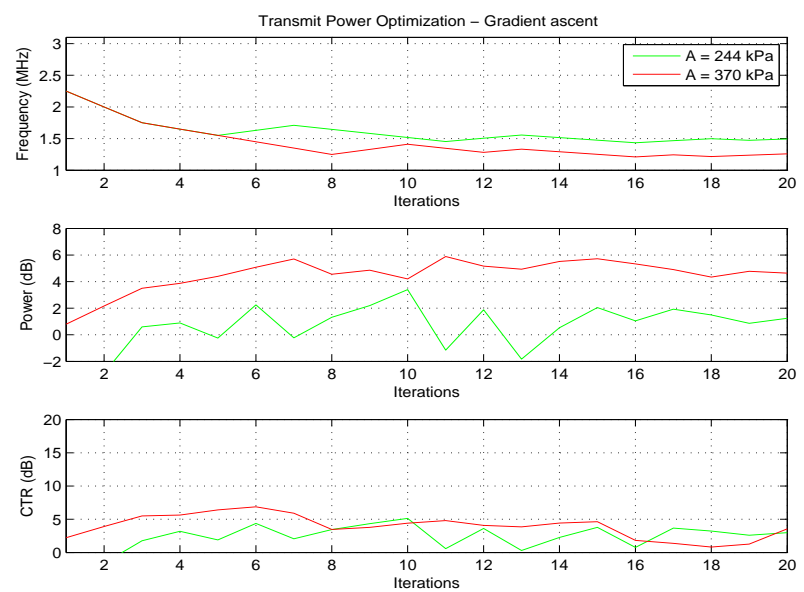

Fig. 7

EXPERIMENT WITH GRADIENT ASCENT

The optimal frequency is different according to the pressure(1.4 MHz and $1.2 \mathrm{MHz}$ respectively for 244 and 370 $\mathrm{kPa})$.

The CTR can reach $10 \mathrm{~dB}$ and in average $5 \mathrm{~dB}$.

For a backscattered power, the maximal pressure could be reduced with an optimal frequency. The reductions are similar to these obtained in simulation. The loss power (LO) was less important when the maximal pressure is reduced (tab III). If a minimal power threshold is fixed, the optimization could increase the duration examination compared with the case without optimization.

\section{Discussions}

These optimization methods of backscattered signals need power according to the frequency to follow a convex curve on the interval in which maximum power is sought. If the interval includes one or several local maxima, the optimization could not find the global maximum and another optimization technique should be found. In case of microbubbles, a local maximum appears for the high pres- sures in simulation. However, all cases have a convex curve and for the hight pressure, the local maximum is near to the global maximum which allows to find it.

The optimal frequencies depend on the transmitted pressure. The backscattered power according to the frequency shows that the maximal power shifts forward the low frequency when the pressure increases. The simulations and the experiments optimal frequencies for the highest pressure are lower than these ones for the lowest pressure. The optimal frequencies obtained in simulation are near to these obtained in experiments.

The CTR is optimized with the maximization of backscattered power. The simulation does not allow to know a CTR, because the blood signal is unknown.

By proposing a close loop system whose frequency adapts itself with the perfused media, throughout the examination, the optimization system adapts itself to the remaining bubbles population thus allowing an increase of the $37 \%$ examination duration. The optimization allows to reduce the maximal pressure. The pression is a factor of the destruction of the microbubbles. With the same power detection level, the examination duration is extended. The GA seems to be more effective than GSS. Indeed, the maximal power search is not limited in an intervals like with GSS.

The experimental results are not exactly identical because of the non-stationarity of microbubbles. To cancel their motion, we have repeated the experiment. But a high number of repetition and a high value of iterations number could destroy the microbubbles and thus the power could decrease. A trade-off must be found to avoid the destruction of the microbubbles.

\section{Conclusion}

The optimization allows to maximize the backscattered power and thus to maximize the CTR. These methods allow to find the optimal frequency adapted to microbubbles. However, these results could be improved if the tissue backscattered power was minimized.

The optimal frequency according to the examination duration could allow an extension duration examination with the decrease of maximal pressure.

We can carry on complicating the optimization, firstly by finding the optimal frequency and the optimal amplitude simultaneously.

\section{Acknowlegdement}

This work was supported by Agence Nationale de la Recherche (Project ANR 07, Tecsan 015, MONitoring response to THERapy with a novel ultrasound technology).

\section{REFERENCES}

[1] F. Tranquart, J.-M. Correas, and A. Bouakaz, Échographie de contraste, Méthodologie et applications cliniques. Paris: Springer, 2007.

[2] W. Press, S. Teukolsky, W. Vetterling, and B. Flannery, Numerical Recipes in $C, 2$ nd ed. Cambridge, UK: Cambridge University Press, 1992.

[3] B. Widrow and S. Stearns, Adaptive Signal Processing (PrenticeHall Signal Processing Series). Englewood Cliffs, New Jersey, USA: Prentice Hall, 1985. 
[4] H. J. Vos, F. Guidi, E. Boni, and P. Tortoli, "Acoustical investigation of freely moving single microbubbles," in Proc. IEEE Ultrasonics Symposium, vol. 2, 18-21 Sept. 2005, pp. 755-758, mean bubble diameter.

[5] K. Chetty, C. Sennoga, J. Hainal, R. Eckersley, and E. Stride, "P1f-4 high speed optical observations and simulation results of lipid based microbubbles at low insonation pressures," in Ultrasonics Symposium, 2006. IEEE, 2-6 Oct. 2006, pp. 1354-1357, shell thickness Shell shear viscosity.

[6] H. Vos, F. Guidi, E. Boni, and P. Tortoli, "Method for microbubble characterization using primary radiation force," Ultrasonics, Ferroelectrics and Frequency Control, IEEE Transactions on, vol. 54, no. 7, pp. 1333-1345, July 2007, gs : Shell shear modulus.

[7] L. Hoff, Acoustic Characterization of Contrast Agents for Medical Ultrasound Imaging. Boston: Kluwer Academic, 2001. 